\title{
ethic@

\section{NEUROCIÊNCIA COGNITIVA E EPISTEMOLOGIA MORAL: SOBRE A IRREDUTIBILIDADE DO SABER AO CONHECIMENTO}

\author{
COGNITIVE NEUROSCIENCE AND MORAL EPISTEMOLOGY: ON THE \\ IRREDUCTIBILITY OF KNOWING-HOW TO KNOWING-THAT
}

\author{
DARLEI DALL'AGNOL ${ }^{1}$ \\ (UFSC/Brasil)
}

\begin{abstract}
RESUMO
Trata-se, neste trabalho, de mostrar a irredutibilidade do saber, em especial do saber moral, ao conhecimento de tipo proposicional. A partir das contribuições da neurociência cognitiva para a epistemologia moral, argumenta-se que o saber-como (knowing-how) não pode ser completamente analisado em termos do saber-que (knowing-that). Critica-se, então, as tentativas recentes, em especial de Stanley, de mostrar que todo conhecimento é proposicional. Finalmente, o trabalho ilustra como o saber moral pode ser identificado em atitudes, por exemplo, saber-como cuidar de um indivíduo vulnerável, saber-como respeitar pessoas etc. A conclusão, então, é que o saber moral não é identificável com o conhecimento factual.

Palavras-chave: Ética; Epistemologia moral; Saber-como; Cuidado.
\end{abstract}

\begin{abstract}
This paper shows that moral knowing-how is non-reducible to knowing-that, that is, to propositional knowledge. Taking into consideration the main contributions of cognitive neuroscience to moral epistemology, it argues that moral knowing-how cannot be analyzed in terms of knowing-that. Afterwards, it criticizes the recent attempts, specially made by Stanley, to show that all knowledge is propositional. Finally, the paper illustrates how moral knowledge can be found in attitudes such as knowing-how to take of a vulnerable individual, knowing-how to respect a person etc. The conclusion then is that moral knowledge is not identical with factual knowledge.
\end{abstract}

Key Words: Ethics, Moral Epistemology; Knowing-how; Care.

\section{Introdução}

Um dos problemas básicos da epistemologia moral diz respeito à existência ou não de conhecimento -e não de meras opiniões- nos domínios da filosofia prática (ética, direito, política etc.). Muitas teorias metaéticas contemporâneas podem ser divididas a partir da resposta positiva (cognitivista) ou negativa (não-cognitivista) a essa questão fundamental. A maioria delas assume que o conhecimento é somente definível em termos de crenças justificadas em proposições verdadeiras, mas esse é um pressuposto que parece comprometer todo o debate. 
Desenvolvimentos recentes, tanto na filosofia quanto na neurociência, parecem colocar em dúvida esse pressuposto equivocado.

O presente trabalho pretende mostrar que, ao contrário da tendência epistemológica predominante de sustentar a redutibilidade de um fenômeno cognitivo ao outro (no intelectualismo, do saber ao conhecimento, mas no pragmatismo do conhecimento ao saber), a neurociência contemporânea encontrou evidências da irredutibilidade do saber ao conhecimento. Por 'redutibilidade' entende-se, aqui, a possibilidade de mostrar certa identidade (como na matemática se reduz a equação 10/10 a 1) entre os supostos tipos de saber demostrando, dessa maneira, que um pode ser completamente analisado nos termos do outro. Para mostrar que o saber moral não é redutível ao conhecimento factual, o famoso caso do paciente H.M. será retomado, juntamente com a distinção entre memória declarativa e memória não-declarativa, e rediscutido no contexto da polêmica entre redutivistas e antiredutivistas na epistemologia. O trabalho, então, pretende investigar a hipótese de que, se é verdade que o desenvolvimento de certas capacidades pode ser feito independentemente de memórias declarativas, então temos uma forte evidência para defender a irredutibilidade do saber moral ao conhecimento factual.

Se o saber não for redutível ao conhecimento, temos que repensar também os debates metaéticos em torno da questão central da epistemologia moral. Nesse sentido, uma das conclusões do trabalho consiste em mostrar a necessidade de compreender o saber moral não apenas em termos de conhecimento, mas de aprendizado de padrões normativos até a sua efetiva internalização. Dessa maneira, podemos construir uma nova epistemologia moral.

\section{1 - Contribuições da neurociência cognitiva para a epistemologia moral}

Há, na neurociência cognitiva, um caso famoso que levou à distinção entre dois sistemas de memória associando-os a dois tipos de conhecimento. Trata-se do paciente H.M. Os principais fatos do caso (extraídos, para as finalidades deste trabalho, de Milner et al., 1998; de Bear et al., 2016; e de um vídeo TED Ed da Australian Academy of Science) são os seguintes:

Aos 10 anos, Henry Molaison, após ter sofrido uma queda de bicicleta que o deixou inconsciente por 5 minutos, começou a ter ataques epilépticos frequentes com fortes convulsões, batimentos da língua, perda de consciência etc. Sob forte medicação diária conseguiu concluir o Ensino Médio e arranjou um trabalho, mas com o passar dos anos a severidade dos choques foi aumentando impossibilitando-o de levar uma vida normal. Em 1953, com 27 anos de idade, submeteu-se a uma cirurgia, feita pelo Dr. Scoville, que extirpou partes do seu cérebro $(8 \mathrm{~cm}$ do lobo temporal medial, partes da amigdala e dois terços do hipocampo) numa tentativa de curá-lo dos ataques 
epilépticos. A retirada dos tecidos não afetou a percepção, inteligência, personalidade etc. de H.M., mas comprometeu seriamente a sua memória. As doutoras Brenda Milner e Suzanne Corkin, do Montreal Neurological Institute, acompanharam H.M. por quase 50 anos e descobriram que ele esquecia eventos rapidamente, não conseguia lembrar números por muito tempo etc. A amnésia foi atentamente estudada, por exemplo, através de exercícios (desenhar uma estrela entre linhas duplas de estrelas já desenhadas olhando apenas a imagem da própria mão no espelho). Tal tarefa exige muita prática para qualquer um. Descobriram, então, que embora H.M. tivesse esquecido de ter feito tais exercícios repetidamente (componente declarativo da memória), ele conseguiu melhorar significativamente o seu desempenho aperfeiçoando as suas habilidades.

Muitos trabalhos foram publicados sobre o caso tornando-o um dos mais estudados da história da neurociência. No artigo Cognitive Neuroscience Review and the Study of Memory, publicado na revista Neuron, a própria Brenda Milner, juntamente com Larry R. Squire e Eric R. Kandel, defendeu a existência de múltiplos sistemas de memória, em especial, a declarativa e a nãodeclarativa, associando-as a tipos de conhecimento numa referência direta à diferenciação feita por Gilbert Ryle entre knowing-that e knowing-how (MILNER, 1998, p.449). O trabalho apresenta um esquema que se tornou padrão na neurociência cognitiva associando a memória declarativa, relacionada a fatos e eventos, ao lobo temporal medial e ao diencéfalo e a memória não-declarativa vinculada a hábitos, habilidades, musculatura e respostas emocionais etc., localizada no cerebelo, no estriado e na amígdala. O segundo tipo de memória depende de condicionamento e é conhecida também como memória procedural.

A associação entre tipos de memória e tipos de conhecimento foi e está sendo muito debatida ainda hoje por neurocientistas e filósofos. Destaca-se, em especial, a divisão entre (i) intelectualistas (por exemplo, BENNETT \& HACKER (2003) e STANLEY (2011)) que sustentam a redutibilidade do saber-como ao conhecimento declarativo, (ii) pragmatistas, ou talvez melhor, praticalistas (entre eles o próprio RYLE, 1949), que sustentam a redutibilidade do conhecimento proposicional ao saber prático considerando-o mais fundamental e (iii) pluralistas como o Wittgenstein das Investigações Filosóficas que não defende a redutibilidade de um ao outro.

Quais são as lições que podemos tirar do caso do paciente H.M.? A maioria dos neurocientistas chegou à conclusão de que há diferenças de tipo entre memória declarativa $\mathrm{e}$ memória não-declarativa, ou seja, que é possível ter uma sem ter a outra. Por exemplo, no livro Neuroscience - Exploring the Brain, os autores concluem: "Esses resultados [dos estudos do paciente H.M.] sugerem que o estriado nos humanos pode desempenhar um papel na memória procedural como parte de um sistema distinto do lobo temporal médio usado pela memória declarativa" (BEAR et al., 2016, p.862). Se isso for verdadeiro e se associarmos corretamente ao problema epistêmico da redutibilidade ou não do saber ao conhecimento, então teremos uma forte evidência empírica a favor da irredutibilidade. Qual é o ponto central que permite corroborar essa hipótese? Em termos neurocientíficos, o fato de que o paciente H.M. conseguiu 
desenvolver certas habilidades sem memória declarativa. De acordo com os mesmos neurocientistas: "Ele aprendeu a desempenhar tarefas novas apesar do fato de que ele não tinha lembrança de certas experiências específicas nas quais ele tinha sido ensinado a fazê-las (o componente declarativo da aprendizagem)" (BEAR et al., 2016, p.842). Portanto, tipos de memória permitiriam concluir que há tipos de saber.

$\mathrm{Na}$ filosofia, entretanto, as dúvidas continuam. Para ilustrar, a posição expressa no livro Philosophical Foundations of Neuroscience, por Bennett e Hacker, parece não dar a devida atenção aos desenvolvimentos da neurociência cognitiva contemporânea, em especial aos inúmeros trabalhos que a centenária Brenda Milner fez sobre esse caso. Como já argumentei em outro lugar (DALL'AGNOL, 2019), a posição de Bennett e Hacker não leva em consideração não apenas os melhores estudos neurocientíficos como também negligencia a gramática filosófica. Como talvez seja amplamente sabido, na sua obra Investigações Filosóficas, Wittgenstein apresenta algumas observações gramaticais sobre as regras de uso de palavras como 'saber' etc. e aponta para as semelhanças do seu significado com 'ser capaz de' (§ 150-151). Infelizmente, essa posição é algumas vezes confundida com a de seu discípulo Gilbert Ryle que não diferenciou knowing-that (aqui traduzido apenas por conhecimento) de knowing-how (significando neste trabalho saber) apenas para criticar o intelectualismo, mas também defendeu a necessidade de reconhecermos que o saber é mais fundamental do que o conhecimento. Ora, esse parece ser um erro parecido com o cometido pelo intelectualista. A posição wittgensteiniana é pela não redutibilidade seja do saber ao conhecimento seja deste àquele apesar de algumas semelhanças de família entre os seus múltiplos usos. Voltarei a esse ponto a seguir.

Embora não se possa extrair diretamente lições normativas dos estudos neurocientíficos, é possível tirar algumas conclusões metaéticas, em especial, de epistemologia moral. Antes de fazê-lo, é necessário, entretanto, aprofundar o debate e resolver o problema da redutibilidade (ou não). Visto que a posição predominante é a favor da redutibilidade do saber-como ao conhecimento proposicional, vou examinar especialmente os argumentos de Jason Stanley de forma crítica. Retornarei às implicações metaéticas na seção seguinte.

\section{2 - O Argumento Intelectualista de Stanley}

Uma das tentativas mais completas de mostrar a redutibilidade do saber (knowing-how) ao conhecimento (knowing-that) foi, recentemente, feita no livro Know how por Jason Stanley. Embora já tivesse publicado anteriormente defendendo o mesmo ponto de vista, nesse livro 
temos uma forma mais sofisticada de procurar analisar redutivamente o uso de uma expressão verbal cognitiva em termos da outra. Em outros trabalhos, já desenvolvi uma crítica à posição epistemológica de Stanley e outros por tentarem uma análise redutiva questionando o uso nada claro que fazem de um "practical mode of presentation" (por exemplo, conferir WILLIAMSON \& STANLEY, 2001) do conhecimento proposicional. Vou procurar, aqui, demonstrar que saber e conhecimento são irredutíveis.

O ponto de partida de Stanley é investigar atribuições de conhecimento a sujeitos cognitivos em contextos específicos. Por exemplo, em que condições podemos dizer que alguém sabe p? Eis alguns empregos de expressões "know-wh" que citarei em inglês para deixar mais evidente o argumento (STANLEY, 2011, p. 36):

* John knows whether Mary came to the party.

* John knows why Obama won.

* Hannah knows who Obama is.

* Hannah knows what she is pointing at.

* Hannah knows how Obama will govern.

De acordo com o autor do livro Know how, em todos esses contextos empregamos sentenças da forma X sabe-que p e não de outro tipo (STANELY, 2011, p.37). Por conseguinte, atribuições de saber como (e saber quando, saber o porquê etc) seriam redutíveis a atribuições de conhecimento.

Para compreender melhor esse ponto, vou discutir um exemplo de saber procedural, supostamente um saber de outro tipo, mas, para o autor de Know how, claramente redutível ao conhecimento. De acordo com Stanley (2011, p.155):

\footnotetext{
O conhecimento procedural é conhecimento que é tipicamente expresso através de um incremento na habilidade. Mas conhecimento de proposições pode ser facilmente expresso através de um incremento de habilidades. Minha crença de que eu devo apanhar uma bola voando [no Baseball] posicionando meu corpo de certa maneira pode tornar-se conhecimento praticando pegar bolas dessa maneira. A prática de pegar bolas dessa maneira me dará evidência proprioceptiva de que minha crença é verdadeira. (itálicos e negritos acrescentados)
}

Esse caso ilustra um dos pontos nos quais o projeto redutivo de Stanley simplesmente falha. $\mathrm{Na}$ verdade, ele parece estar confundindo causas e efeitos como fica claro na parte ressaltada da citação acima. Crenças, por si só, não geram habilidades, embora estas possam gerar aquelas. Em outros termos, a prática do jogo de baseball é condição necessária para saber-como correr. Não basta ter crenças sobre certa postura corporal (correr com o braço fechado, com os ombros posicionados de certa maneira etc.) para realizar, com sucesso, a ação de apanhar a bola. Não 
basta crer que tenho que apanhar a bola para efetivamente apanhá-la. Se, depois de praticar e realizar a ação com sucesso surgir a crença de que se é capaz de fazê-la, isso não prova que a crença produz a habilidade. Aqui temos diferenças claras entre um aprendiz (alguém que não sabe-como ainda), que precisa ouvir uma série de proposições verdadeiras e instruções normativas sobre o que fazer, e um profissional (uma pessoa que sabe como correr com o braço adequadamente fechado, com os ombros posicionados etc.), isto é, alguém que já internalizou uma série de padrões de correção e efetivamente desenvolveu a capacidade de apanhar a bola. Em outros termos, ter crenças não é suficiente: o treinamento, as repetições etc., enfim, a habituação é condição para desenvolver capacidades. Podemos concluir, então, que a prática é constitutiva do saber-como.

Outro erro de Stanley parece advir da falta de distinção mais clara entre empregos de know-wh, particularmente, de knowing-how. Aqui, então, vou inicialmente conceder que pode haver, para usar um conceito wittgensteiniano, algumas semelhanças de família entre sabercomo e saber-que. Por exemplo, a sentença "Hannah knows how Obama will govern," pode ser analisada (talvez até mesmo de forma redutiva) em outras sentenças usando know that: Hannah knows that Obama is a democrat, not a republican politician; Hannah knows that Obama is truly committed to the democrat policies; Hannah knows that democrat voters want a universal healthcare system; Hannah knows that Obama is devoted to the same public policy; Hannah knows that Obama takes action to implement the healthcare system ... etc. Esse uso particular de know how (ou Hannah sabe como Obama vai governar) parece ser redutível a sentenças contendo expressões de conhecimento proposicional.

Há um emprego, todavia, de 'know how' que, embora tenha semelhanças de família com esse uso redutível, possui uma característica diferenciadora que impossibilita a redutibilidade. Mantendo o mesmo exemplo: para saber-como jogar baseball é necessário aprender a correr apropriadamente a fim de apanhar a bola. Em outros termos, a corrida precisa ser feita de certa maneira e somente aprende-se praticando como correr com aquela postura do corpo, ou seja, com o braço fechado, com os ombros bem posicionados e assim por diante. Novamente, a prática é condição necessária para adquirir saber-como e não importa o número de proposições verdadeiras que um sujeito conheça, daí não se segue que ele saiba-como jogar baseball.

A independência desse último tipo de saber-como pode ser claramente percebida, voltando ao caso do paciente H.M., pelo fato de que ele aprendeu e desenvolveu técnicas de desenhar uma estrela no meio de duas linhas com estrela dupla olhando apenas para a imagem de sua mão no espelho. O desenvolvimento dessa habilidade sem o componente da memória 
declarativa, pois ele não lembrava que tinha feito os exercícios anteriormente e era como se começasse sempre novamente embora progredisse a cada dia, mostra, ao menos, a independência dos sistemas de memória. Enfim, mostra que saber e conhecimento são fenômenos cognitivos de tipo diferente. Se esse ponto está bem estabelecido, então pode-se dizer que Stanley não considerou seriamente as implicações de alguns desenvolvimentos da psicologia cognitiva e da neurociência atual.

Nas línguas latinas temos, felizmente, um recurso linguístico para distinguir a diferença cognitiva entre saber (derivado da palavra latina sapere, originalmente significando "ter gosto") e conhecimento, embora seja necessário ressaltar que não se trata apenas de uma questão semântica, mas sim de seguir regras de uso em contextos determinados para que lhes determinemos o real significado. Por exemplo, na língua francesa, a expressão savoir-faire (mais relacionado a habilidades de fazer e agir) difere significativamente de connaitre empregado majoritariamente para eventos e fatos. Essa diferença aparece também na língua portuguesa entre saber e conhecer e foi esclarecida pela neurociência como sendo associável a sistemas de memória independentes. Agora, embora seja um uso pouco comum, a língua inglesa começa a usar, além do verbo know, outros verbos para expressar estados cognitivos, em especial o verbo cognize. Por exemplo, Chomsky introduziu esse uso no livro Rules and Representations denotando um saber tácito relacionando um sujeito cognoscente com o próprio conhecimento. Por exemplo, nem todo falante nativo de uma língua conhece explicitamente as regras que normalizam o uso das palavras, expressões etc. Claro que esse saber pode ser explicitado, mas Chomsky salienta, embora nem sempre com o devido rigor, que ele é tácito, não-consciente etc. e distinto do mero conhecimento. Por isso, melhor seria usar 'cognize' e não apenas 'knowing-how,' pois há um elemento cognitivo na apreensão de regras que é uma espécie de saber tácito como condição para o desempenho competente das práticas linguísticas. Felizmente, na língua portuguesa podemos diferenciar tipos de saber e, em especial, cunhar tecnicamente um emprego para o "conhecer" salientando os aspectos proposicionais em contrapartida aos aspectos práticos do saber.

Essa diferenciação entre tipos de conhecimento permite recolocar a questão metaética em termos menos simplistas. Por exemplo, os positivistas lógicos tinham uma compreensão intelectualista de conhecimento definindo-o apenas em termos proposicionais ou representacionais e, por esse motivo, acabaram defendendo formas de não-cognitivismo na epistemologia moral, em especial, teorias emotivistas. Ora, se negamos o pressuposto básico que existe conhecimento apenas proposicional, então é possível defender formas mais sofisticadas de teorias metaéticas. Esse é o ponto que será brevemente apresentado a seguir. 


\section{3 - Sobre a irredutibilidade do saber moral}

Tendo mostrado os equívocos da posição de Stanley, iremos, nesta última seção, apresentar um argumento positivo para mostrar a irredutibilidade do saber moral ao conhecimento factual. O objetivo principal será defender uma nova concepção cognitivista na epistemologia moral mostrando que o saber moral é sui generis e que a Ética é uma disciplina independente tanto de ciências empíricas, que eventualmente também estudam os fenômenos morais tais como a sociologia, a etnologia etc. quanto de fundamentações metafísicas, em especial, as religiosas. Dito de outro modo, o objetivo principal é mostrar que a Ética possui seus próprios procedimentos metodológicos e também os seus modos específicos de justificação.

Para não ficarmos com uma crítica apenas negativa aos redutivistas, podemos apresentar, agora, um argumento para demonstrar a irredutibilidade do saber ao conhecimento. Uma premissa básica pode ser enunciada deste modo: se crenças justificadas em proposições verdadeiras não são suficientes para aprender a $\varphi r$ (uma atividade qualquer como dirigir, nadar, jogar xadrez, cuidar de indivíduos vulneráveis etc.), então, o saber não é redutível ao conhecimento. Estamos usando, aqui, 'crença' como uma atitude mental de aceitação preliminar da verdade de uma representação proposicional. Ora, ter crenças, mesmo que verdadeiras, parece não ser suficiente para saber-como praticar certas atividades, por exemplo, jogar baseball, dirigir um automóvel, cuidar de indivíduos vulneráveis etc. Por isso, outra premissa fundamental do argumento consiste em estabelecer que é condição necessária desenvolver certo treinamento para adquirir as habilidades distintivas para desempenhar a atividade em questão. Em outros termos, praticar os atos constitutivos da atividade é condição sem a qual não é possível adquirir o saber em questão. Aqui, a prática consiste basicamente na internalização de certos padrões normativos que são constitutivos da atividade $\varphi r$. Para lembrarmos dos tipos de memória apresentados acima, é necessário desenvolver uma memória corporal, não declarativa, ajustando nossos comportamentos àquilo que é requerido para um desempenho com sucesso da atividade. A performance torna-se habitual, uma memória corporal, não consciente. A conclusão, por conseguinte, que podemos tirar é que o saber não é redutível ao mero conhecimento proposicional.

Há um ponto que precisa ser enfatizado aqui. Conforme foi estabelecido acima, a partir dos estudos neurocientíficos sobre o paciente H.M., o caso mostra que a memória declarativa, relacionada a fatos e eventos, está localizada principalmente no lobo temporal medial e no 
diencéfalo e que a memória não-declarativa, relacionada a hábitos, habilidades, musculatura e respostas emocionais etc., está vinculada ao cerebelo, amígdala, estriado etc. Ora, ao defender que a memória não-declarativa, responsável pelo desenvolvimento de hábitos e que pode ser associada ao saber-como, alguém poderia concluir que uma ética de virtudes teria respaldo neste tipo de estudos neurocientíficos. De fato, alguns neurocientistas trabalham com um referencial normativo aretáico enquanto a maioria é utilitarista. Todavia, conforme alertamos acima, os estudos neurocientíficos podem ser usados apenas para fins metaéticos, mas não para tirar conclusões normativas.

O ponto, aqui, é apenas estabelecer se o saber moral existe e se é um subtipo de sabercomo. Conforme já argumentei, é razoável compreender o saber moral como uma expressão de um saber-como, por exemplo, quando atribuímos a uma pessoa saber ou não saber respeitar outra pessoa ou saber-como cuidar de um indivíduo vulnerável (cf. ANDRADE \& AZEVEDO, 2020, para uma discussão sobre respeito pelas pessoas). Não se trata, então, de um mero conhecimento técnico, mas efetivamente de ter aprendido a, por exemplo, seguir normas morais que exigem, somente para ilustrar, que se incremente o bem-estar do outro valorando-o intrinsecamente. Para um cognitivista prático, então, saber-como agir moralmente pressupõe que se seja capaz de valorar intrinsecamente as pessoas ou seres vulneráveis. A especificidade da moralidade consiste exatamente na ideia de que esse tipo de valor se sobrepõe aos demais. Diferentemente do saber não-moral, por exemplo, de um mosaicista que sabe-como produzir uma obra de arte, um agente moral precisa saber-como agir respeitosamente, ser uma pessoa cuidadosa etc. O que o caso do paciente H.M. nos mostra é que há sistemas de memória independentes e que, associados a fenômenos cognitivos, torna claro que o saber moral não é redutível ao conhecimento. Dito de outro modo, é possível internalizar padrões normativos tais como os que estão presentes em atividades como cuidar (por exemplo, não causar mais danos que benefícios) independentemente do conhecimento. Isso pode ser comprovado, também, pelo fato de que há pessoas que conhecem muito, mas não agem moralmente. Certos cientistas famosos foram no cotidiano pessoas de caráter duvidoso ou efetivamente más. Nenhuma dose de conhecimento torna as pessoas melhores. Psicopatas podem ter um conhecimento muito grande, mas serem incapazes de colocar-se no lugar de uma outra pessoa e agir moralmente. Disso não se segue, todavia, que ter crenças suficientemente justificadas em proposições verdadeiras não seja constitutivo também das práticas humanas (por exemplo, cuidar de indivíduos vulneráveis.) É por isso que um profissional da saúde, responsável e capaz de agir moralmente, cuida melhor de indivíduos vulneráveis do que uma pessoa amadora, ou seja, ela tem também conhecimento científico. 
Não é possível, aqui, tratar de todas as questões epistêmicas necessárias para compreender de forma geral o que é sustentado a partir do cognitivismo prático, mas há um ponto que não foi desenvolvido ainda e que merece uma atenção especial. Dito de outro modo, já apresentamos uma análise conceitual do saber-como, um critério diferenciador do saber moral dos outros subtipos de saber, uma discussão sobre a possível noção de verdade associável a esse tipo de saber, se ele requer uma justificação fundacionista ou se é falível, respondemos algumas objeções etc. (cf. DALL'AGNOL, 2019, para uma exposição desses pontos). Resta, todavia, apresentar uma compreensão mais exata da natureza desse saber moral. Há tentativas de mostrar que o próprio conhecimento moral, entendido em termos de crenças justificadas, poderia ser explicado por uma metaética expressivista (cf. BONELLA, 2020). O autor de "Em busca do conhecimento moral," procura mostrar que a objetividade, a racionalidade e a própria noção de verdade, definida apenas em termos correspondenciais, podem ser compreendidas e explicadas a partir do expressivismo. Entretanto, se esse for o caso, não fará mais sentido qualificar tal posição de não-cognitivista, embora o esforço pareça ir na direção certa para fornecer uma compreensão mais adequada de $u m$ dos jogos de linguagem da moral. Como tentamos mostrar aqui, há outros jogos de linguagem moral que evidenciam fenômenos cognitivos baseados em um outro tipo de saber que não o proposicional. Parece evidente que usamos a palavra 'moral' para cobrir uma série de comportamentos que vão desde os que pensamos que devem ser proibidos (por exemplo, homicídios) até ações beneficentes que são simplesmente louvadas. A questão, então, é estabelecer se todos são fenômenos cognitivos.

Não é possível, nem foi, na verdade, objetivo deste trabalho apresentar uma resposta acabada para essa questão. A vida moral é complexa e uma eventual descrição fenomenológica completa claramente precisa identificar uma série de ingredientes entrelaçados das mais diferentes maneiras. Com um pouco de reflexão podemos perceber que uma moral é composta por sentimentos (tanto positivos como simpatia, empatia etc. quanto negativos, tais como, ressentimento, culpa e assim por diante), hábitos que se tornam vícios ou qualidades de caráter, normas gerais ou princípios universais bem como regras particulares que prescrevem atos específicos etc. Conforme foi alertado, não é objetivo fazer uma descrição completa desses elementos aqui. Também não é minha intenção descortinar os entrelaçamentos entre esses ingredientes. Todavia, parece adequado assumir que alguns deles são suficientemente objetivos para podermos atribuir aos agentes saber moral. Para ilustrar, um princípio que justifica muitas práticas nas ciências da saúde é a norma básica não causar mais danos que benefícios e absterse de agir quando somente resulta dano. Ora, quando educamos moralmente alguém para que possa cuidar de indivíduos vulneráveis não podemos prescrever diferentemente. No final, então, 
podemos apenas dizer que um agente sabe (ou não) cuidar de alguém se ele efetivamente é capaz de seguir aquela norma fundamental, entre outras, e o faz motivado adequadamente, isto é, cuida da outra pessoa porque isso é bom para ela reconhecendo-lhe o devido valor. É este tipo especial de saber que um cognitivista prático tem em mente quando sustenta que existe cognição moral e que ela envolve saber-como e não apenas conhecimento.

\section{Observações Finais}

Se o saber moral não for redutível ao conhecimento proposicional, como argumentamos neste trabalho, então precisamos repensar também os debates metaéticos em torno da questão central da epistemologia moral. Nesse sentido, uma das implicações deste trabalho parece apontar para a necessidade de compreender o saber moral em termos de aprendizado de padrões normativos até a sua efetiva internalização e o desenvolvimento de capabilidades morais adequadas (mesmo que compreendidas disposicionalmente). De um modo geral, então, a posição adotada pelo cognitivista prático parece mais adequada do que aquela assumida pelos não-cognitivistas, seja de que matiz for (emotivistas, expressivistas, quase-realistas, ficcionalistas etc.) e pelos defensores do ceticismo ético.

\section{Nota}

1 Professor Titular da Universidade Federal de Santa Catarina (UFSC), Florianópolis, SC., Brasil. E-mail: ddarlei@yahoo.com

Trabalho apresentado no 11th Principia International Symposium (20/08/19). Agradeço aos participantes pelas discussões e ao CNPq pelo apoio ao meu projeto atual de pesquisa "Fundamentos Filosóficos da Neurobioética." 


\section{Referências}

ANDRADE, B., AZEVEDO, M. A. Respeitando Biografias Até o Fim. ethic@ V.19, N.1, 2020 (a ser publicado neste volume).

AUSTRALIAN ACADEMY OF SCIENCE. The Hippocampus \& Memory (PET Ed) (https://www.science.org.au/curious/video/hippocampus )

BEAR, M.F., CONNORS, B. W., PARADISO, M.A. Neuroscience - Exploring the Brain. New York: Wolters Kluwer, 2016.

BENGSON, J., MOFFETT, M.A. Knowing-how-Essays on Knowledge, Mind, and Action. Oxford: Oxford University Press, 2011.

BENNET, M.R. \& HACKER, P.M.S. Philosophical Foundations of Neuroscience. Oxford: Blackwell, 2003.

BONELLA, A. Em busca do conhecimento moral. ethic@ V.19, N.1, 2020 (a ser publicado neste volume).

CHOMSKY, N. Rules and Representations. New York: Columbia University Press, 1980.

DALL'AGNOL, D. Saber moral: fundamentos epistêmicos da neurobioética. Filosofia

Unisinos, v. 20, n. 1, p. 65-75, jan/apr. 2019. doi: 10.4013/fsu.2019.201.08

MAXWELL, N. From knowledge to wisdom. London: Blackwell, 2007.

MILNER, B., SQUIRE, L.R., KANDEL, E.R. Cognitive Neuroscience Review and the Study of Memory. Neuron. Vol. 20, March, 1998. p. 445-468.

RYLE, G. The Concept of Mind. New York: Banes \& Nobles, 1949.

STANLEY, J. Know how. Oxford: Oxford University Press, 2011.

WILLIAMSON, T. \& STANLEY, J. Knowing-how. The Journal of Philosophy. XCVII, p. 411-444.

WITTGENSTEIN, L. Philosophical Investigations. Oxford: Blackwell, 2016. 